\title{
Molecular detection of Mayaro virus during a dengue outbreak in the state of Mato Grosso, Central-West Brazil
}

\author{
Nayara Zuchi', Letícia Borges da Silva Heinen', Marcelo Adriano Mendes dos Santos², \\ Fernanda Carla Pereira1, Renata Dezengrini Slhessarenko ${ }^{1 /+}$
}

1Programa de Pós-Graduação em Ciências da Saúde, Faculdade de Medicina, Universidade Federal de Mato Grosso, Cuiabá, MT, Brasil ${ }^{2}$ MT Laboratório, Secretaria Estadual de Saúde, Cuiabá, MT, Brasil

Mayaro virus (MAYV) is frequently reported in Pan-Amazonia. The aim of this study was to investigate the circulation of alphaviruses during a dengue outbreak in the state of Mato Grosso, Brazil. Serum samples from denguesuspected patients were subjected to multiplex semi-nested reverse transcriptase polymerase chain reaction for 11 flaviviruses and five alphaviruses, to nucleotide sequencing and to viral isolation. MAYV was detected in 15 (2.5\%) of 604 patients. Twelve were co-infected with dengue virus 4, which was isolated from 10 patients. The molecular detection of MAYV in dengue-suspected patients suggests that other arboviruses may be silently circulating during dengue outbreaks in Brazil.

Key words: Mayaro virus - dengue virus 4 - Mato Grosso

Mayaro virus (MAYV) is an arbovirus belonging to the Semliki Forest antigenic serocomplex of the $\mathrm{Al}$ phavirus genus in the Togaviridae family (Vasconcelos et al. 1998). MAYV was first isolated from rural workers in Trinidad in 1954; since then, viral isolation and serologic response have been reported in South America (Anderson et al. 1957, Talarmin et al. 1998, Vasconcelos et al. 1998, Forshey et al. 2010).

MAYV is believed to be maintained in sylvatic and rural cycles in tropical South America involving primarily Haemagogus janthinomys mosquitoes as vectors and non-human primates and birds as primary and secondary hosts, respectively. Human infections are generally sporadic and accidental (Abad-Franch et al. 2012).

Mayaro fever is a mild, self-limited acute febrile illness characterised by transient viraemia lasting three-five days, which is accompanied by rash, fever, malaise, headache, eye pain, myalgia and arthralgia that may last for several days or weeks (Pinheiro et al. 1981, Azevedo et al. 2009).

In South America, MAYV circulates primarily in the Amazon Region. The non-specific clinical presentation of Mayaro fever is often confused with that of dengue fever (Pinheiro et al. 1981, Azevedo et al. 2009), which is widespread and occurs frequently in Brazil. Laboratory diagnosis has been directed toward infection with this flavivirus, which could prevent the identification of other important arboviruses eventually circulating in the population, including those never before reported in Brazil. In this regard, molecular investigations are useful for population screening and arboviral differential diagnosis.

doi: 10.1590/0074-0276140108

Financial support: CNPq, CAPES, UFMT

+ Corresponding author: renatadezengrini@yahoo.com.br

Received 26 March 2014

Accepted 27 June 2014
In Brazil, MAYV outbreaks have been reported periodically in the North Region since the 1950s, including in the states of Pará (PA) and Amazonas (AM) (Azevedo et al. 2009, Nunes et al. 2009, Mourão et al. 2012). In contrast, Mayaro fever has not often been reported in other regions of the country. There are, however, a few reports in Central-West Brazil, including the states of Goiás and Mato Grosso do Sul (MS) (Pinheiro et al. 1981, Vasconcelos et al. 1998, Coimbra et al. 2007). In the state of Mato Grosso (MT), the largest in the region, the only report of MAYV circulation involved serological evidence among native Brazilian Xavante Indians in 1968 (Neel et al. 1968).

Recently, MAYV was reported in urban/periurban areas and was associated with nocturnal transmission cycles in Manaus, AM, highlighting concerns about the potential urbanisation of Mayaro fever in Brazil (AbadFranch et al. 2012, Mourão et al. 2012).

Considering there are no recent data demonstrating MAYV circulation in MT and given that alphavirus infections - including Mayaro fever - are often confused with dengue fever, the main objective of the present study was to conduct a molecular investigation for alphaviruses in patients during a large dengue fever outbreak.

Patients presenting with acute febrile illness for no more than five days and who sought medical attention at health-care facilities in 20 MT municipalities between October 2011-July 2012 were included in the study. Research involving humans had been pre-approved by the institutional Ethical Committee (Júlio Muller University Hospital, protocol 100/2011).

The 604 acute serum samples obtained were subjected to RNA extraction using a commercial kit (QIAamp ${ }^{\circledR}$ Viral RNA Mini Kit, Qiagen Inc) in accordance with the manufacturer's instructions. The extracted RNA was subjected to a duplex semi-nested reverse transcriptase polymerase chain reaction (PCR) for an NS5 gene region of flaviviruses and an NSP1 gene region of alphaviruses. This was followed by species-specific multiplex semi-nested PCR for MAYV, Aura virus, Eastern, Western and Venezuelan 
equine encephalitis viruses and a species-specific multiplex semi-nested PCR for dengue virus (DENV) serotypes and seven other flaviviruses (Bronzoni et al. 2005).

Fifteen out of 604 patients $(2.5 \%)$ were positive for MAYV RNA, with the breakdown in Cuiabá (9/15), Várzea Grande (3/15), Sorriso (2/15) and Nossa Senhora do Livramento (1/15). All these cities are located in the Cerrado biome (Fig. 1). Samples positive for MAYV RNA were tested at least twice in independent reactions. Single nested-PCR amplicons obtained with the same primers for MAYV NSP1 gene (270 nt) were sequenced (3500 Genetic Analyzer, Applied Biosystems, USA) and analysed using Geneious R7 (v.7.0.7, USA) and Basic Local Alignment Search Tool (PubMed) to confirm amplification. The sequences were deposited at GenBank and PubMed. Positive samples were also subjected to viral isolation using Vero and C6/36 cells (Figueiredo et al. 1992).

The MAYV-positive samples were collected between January-May 2012, a period that offers environmental conditions favourable to vector proliferation and arboviruses activity. Of the 15 patients positive for MAYV RNA, 12 (80\%) were also positive for DENV-4 RNA; two patients from Cuiabá and one from Sorriso (20\%) were positive only for MAYV. DENV-4 was isolated in C6/36 cells from 10 out of the 12 co-infected patients. However, attempts at MAYV isolation were unsuccessful. Possible explanations are the limitations described for MAYV recovery during outbreaks from the sera of human hosts, namely low viral titres, transient viraemia

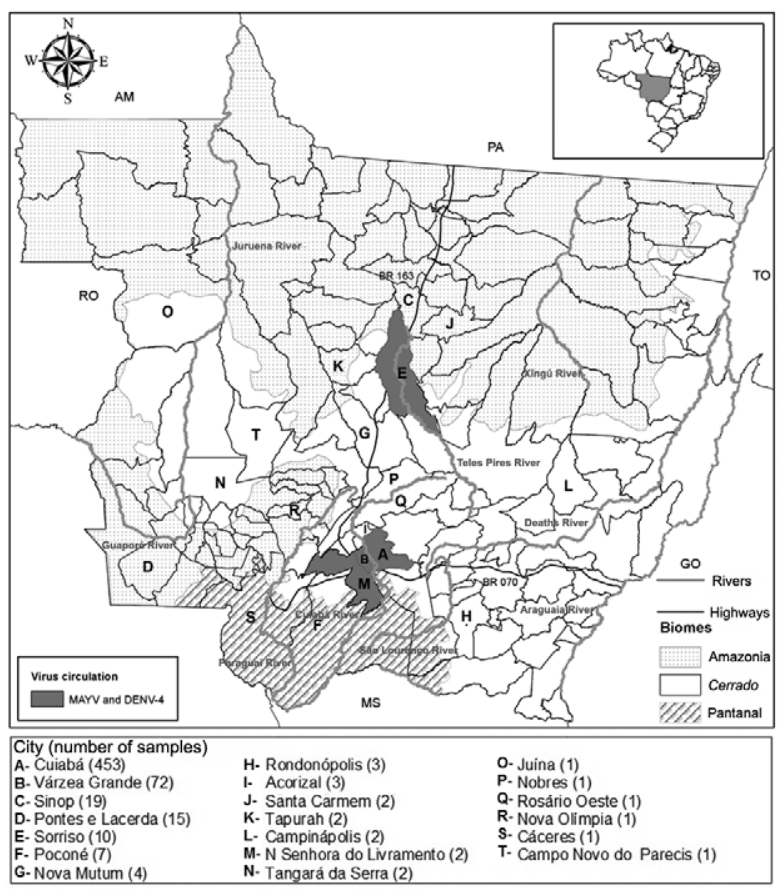

Fig. 1: distribution of patients with acute febrile illness from the state of Mato Grosso (MT), Brazil, investigated for arbovirus during a dengue outbreak in 2012. Cities with patients positive for Mayaro virus (MAYV) RNA and/or dengue virus 4 (DENV-4) are identified. Brazilian states: Amazonas (AM), Mato Grosso do Sul (MS), Pará (PA), Rondônia (RO), Tocantins (TO). and viral RNA degradation (Talarmin et al. 1998, Vasconcelos et al. 1998, Coimbra et al. 2007, Azevedo et al. 2009, Mourão et al. 2012).

The 12 co-infections identified most likely occurred due to the large outbreak of dengue observed in MT in 2012 , when 44,814 cases were reported, with $96.2 \%$ being attributed to the recently introduced DENV-4 and 3.8\% to DENV-1 (MS 2012). Cuiabá presented the majority of the cases, with 10,742 documented cases, followed by Várzea Grande, with 3,133 documented cases (SES-MT 2013). The patients enrolled in this study sought medical attention after developing acute febrile symptoms for five or fewer days. As MAYV infections are frequently accompanied by transient viraemia (Vasconcelos et al. 1998), this aspect combined with the absence of routine differential diagnosis may contribute to the silent circulation of MAYV during dengue outbreaks.

The nucleotide sequences obtained from MAYVpositive patients presented $80-100 \%$ identity with sequences from the reference strain Brazil and other MAYV isolates obtained from human and arthropods in different periods, such as BeH343148 isolated in PA (1978) and Uruma from Bolivia (1955), both belonging to genotype D, and BeAr505411 from PA (1991), which is classified as genotype L (Table).

Most of the MAYV-positive patients (14/15; 92.7\%) were 15-59 years old and both sexes were affected equally (Fig. 2). All positive patients described themselves as urban residents (Fig. 1), without a recent history of travel or access to rural or sylvatic areas. This indicates that MAYV may not be restricted to sylvatic or rural cycles

A
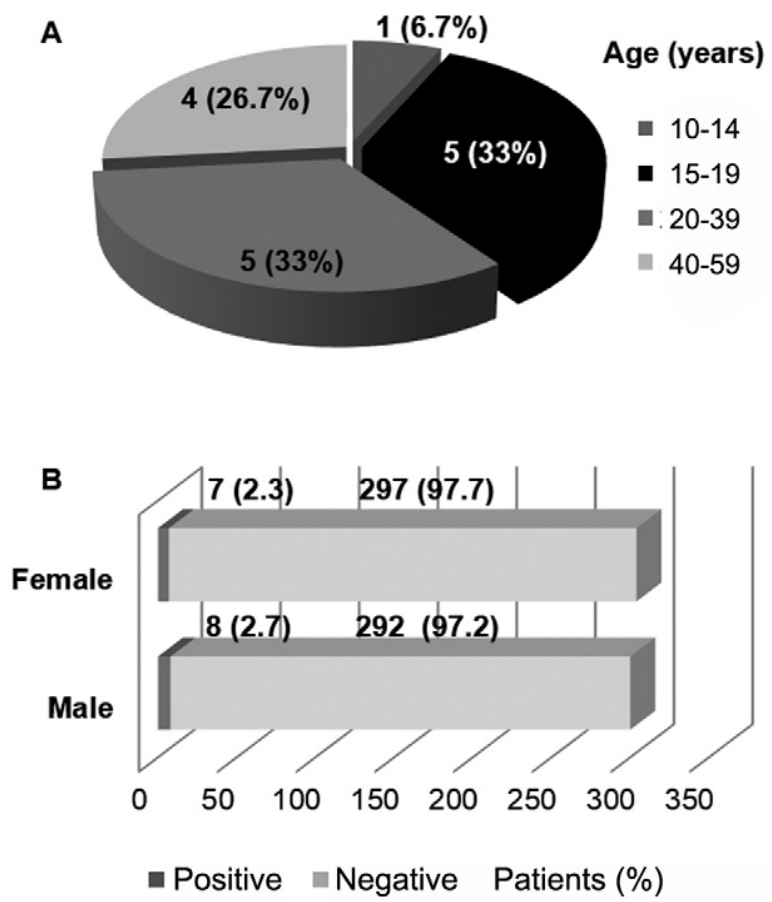

Fig. 2: prevalence of Mayaro virus in febrile patients from municipalities of the state of Mato Grosso, Brazil, during a dengue outbreak in 2012, according to patient age (A) and gender (B). 
TABLE

Clinical and epidemiological data of patients with acute febrile illness for fewer than five days from the state of Mato Grosso, Brazil, positive for Mayaro virus (MAYV) RNA or co-infected with dengue virus 4 (DENV-4) - 2012

\begin{tabular}{|c|c|c|c|c|c|c|}
\hline $\begin{array}{l}\text { Patient } \\
\mathrm{n} \text { (age) }\end{array}$ & Sex & Occupation & City of origin & $\begin{array}{l}\text { Clinical signs and simptoms and history } \\
\text { of previous similar disease }\end{array}$ & RT-PCR & $\begin{array}{l}\text { GenBank } \\
\text { accessions }\end{array}$ \\
\hline $9(43)$ & $\mathrm{F}$ & Housekeeper & Cuiabá & $\begin{array}{l}\text { Hyperthermia, myalgia, arthralgia, nausea, } \\
\text { petechiae, pruritus, retrorbital pain }\end{array}$ & DENV-4/MAYV & KJ682316 \\
\hline $12(10)$ & $\mathrm{F}$ & Student & $\begin{array}{l}\text { Nossa Senhora } \\
\text { do Livramento }\end{array}$ & $\begin{array}{l}\text { Hyperthermia, myalgia, } \\
\text { headache, retrorbital pain }\end{array}$ & DENV-4/MAYV & KJ879255 \\
\hline $20(19)$ & M & Salesman & Várzea Grande & $\begin{array}{l}\text { Hyperthermia, myalgia, } \\
\text { headache, prostation, emesis }\end{array}$ & DENV-4/MAYV & KJ713282 \\
\hline $22(40)$ & $\mathrm{F}$ & Nurse & Várzea Grande & $\begin{array}{l}\text { Hyperthermia, myalgia, } \\
\text { prostation, retrorbital pain }\end{array}$ & DENV-4/MAYV & KJ879258 \\
\hline $127(16)$ & M & Student & Cuiabá & $\begin{array}{l}\text { Hyperthermia, myalgia, } \\
\text { headache, retrorbital pain }\end{array}$ & DENV-4/MAYV & NA \\
\hline 147 (48) & $\mathrm{F}$ & Seamstress & Várzea Grande & $\begin{array}{l}\text { Hyperthermia, myalgia, arthralgia, } \\
\text { headache, retrorbital pain, petechiae }\end{array}$ & DENV-4/MAYV & KJ739869 \\
\hline 220 (17) & M & Salesman & Cuiabá & $\begin{array}{c}\text { Hyperthermia, headache, } \\
\text { dizziness, nausea }\end{array}$ & DENV-4/MAYV & NA \\
\hline $230(20)$ & M & Bricklayer & Cuiabá & $\begin{array}{l}\text { Hyperthermia, myalgia, } \\
\text { headache, retrorbital pain, emesis }\end{array}$ & DENV-4/MAYV & KJ879253 \\
\hline $246(18)$ & M & Inmate & Sorriso & $\begin{array}{l}\text { Hyperthermia, myalgia, arthralgia, } \\
\text { headache, retrorbital pain, nausea }\end{array}$ & MAYV & KJ879333 \\
\hline $301(42)$ & M & Salesman & Cuiabá & $\begin{array}{l}\text { Hyperthermia, myalgia, } \\
\text { arthralgia, retrorbital pain }\end{array}$ & MAYV & KJ879259 \\
\hline $305(20)$ & M & Deliveryman & Cuiabá & Hyperthermia, headache, retrorbital pain & DENV-4/MAYV & KJ879254 \\
\hline $306(20)$ & $\mathrm{F}$ & Auxiliary & Cuiabá & Hyperthermia, myalgia: dengue infection & MAYV & KJ879256 \\
\hline $308(16)$ & $\mathrm{F}$ & $\begin{array}{l}\text { Telemarketing } \\
\text { attendant }\end{array}$ & Cuiabá & $\begin{array}{l}\text { Hyperthermia, headache, } \\
\text { prostation, retrorbital pain }\end{array}$ & DENV-4/MAYV & KJ879257 \\
\hline $322(21)$ & $\mathrm{F}$ & Receptionist & Cuiabá & $\begin{array}{l}\text { Hyperthermia, headache, prostation, } \\
\text { retrorbital pain, anorexia }\end{array}$ & DENV-4/MAYV & KJ870987 \\
\hline $618(33)$ & M & Salesman & Sorriso & Hyperthermia, headache, myalgia & DENV-4/MAYV & NA \\
\hline
\end{tabular}

F: female; M: male; NA: not available; RT-PCR: reverse transcriptase polymerase chain reaction.

in MT, as observed in Manaus, AM (Abad-Franch et al. 2012, Mourão et al. 2012). Mayaro prevalence is generally higher among adult male with occupations related to sylvatic or rural environments (Azevedo et al. 2009). However, no differences regarding gender, age (Fig. 2) or occupation (Table) were observed in this study. These findings may corroborate the occurrence of urban transmission cycles. However, it is worth noting that is difficult to determine the boundaries between urban and rural/sylvatic areas in some cities in Central-West Brazil. Thus, further studies focused on entomological surveillance are necessary to evaluate MAYV potential transmission cycles in MT.

The patients who were positive only for MAYV RNA presented hyperthermia, myalgia, arthralgia, headache, retro-orbital pain and nausea (Table). Those also positive for DENV-4 RNA reported hyperthermia (100\%), retro-orbital pain $(75 \%)$, headache $(83.3 \%)$, myalgia $(66.6 \%)$, prostration $(33.3 \%)$, arthralgia $(16.6 \%)$, nausea $(16.6 \%)$, emesis $(16.6 \%)$, petechiae (16.6\%) and anorexia (8.3\%) (Table).
The detection of DENV and MAYV highlights the importance of differential diagnosis in patients with suspected dengue fever. Chikungunya virus (CHIKV), another alphavirus of the same serocomplex as MAYV and producing clinical infection similar to dengue fever, was recently introduced in the Caribbean. Similar to DENV, $\mathrm{CHIKV}$ has lost the requirement for sylvatic amplification, producing extensive urban epidemics involving $\mathrm{Ae}$ des aegypti and Aedes albopictus as vectors (Enserink 2014). Considering that Central America is a common route for DENV serotype introduction into Brazil and these vector species are widely dispersed in the country, there is a concern about the introduction and rapid spread of CHIKV in Brazil.

$H$. janthinomys, the main vector of MAYV, predominates in sylvatic areas. However, natural infection by MAYV of Psorophora and Mansonia species and experimental transmission by Aedes and Culex species has been demonstrated (Aitken et al. 1960, Galindo \& Srihongse 1967, Smith \& Francy 1991). Species of $\mathrm{Cu}-$ 
licidae potentially associated with MAYV transmission are currently being investigated in the urban area of Cuiabá, where the vast majority of MAYV-positive patients were identified. Whether the co-infections by DENV-4 and MAYV identified in this study are the result from exposure to co-infected vector mosquitoes or to multiple infected vector species in a short period is unknown. Competitive suppression of CHIKV replication in $\mathrm{C} 6 / 36$ cells during co-infection occurs when DENV is inoculated in higher titres (Potiwat et al. 2011). However, studies involving co-infections by DENV and alphaviruses, including MAYV, in vector species are lacking.

MAYV was previously reported in neighbouring states, including virus isolation from a patient regressing from Camapuã, MS (Coimbra et al. 2007) and serologic response indicating recent infection in residents from cities in PA affected by the Cuiabá-Santarém Highway (Nunes et al. 2009). The present study suggests human acute infection by MAYV in MT. Entomological and epidaemiological surveillance strategies are necessary to confirm the current circulation of the virus in the state.

The molecular detection of MAYV in febrile patients suspected of having dengue suggests that other arboviruses may be silently circulating during dengue outbreaks in MT. Our findings also point to the necessity of differential diagnoses to detect future introductions of arboviruses associated with dengue-like illness, but not previously reported in the country, such as CHIKV, during dengue fever outbreaks.

\section{ACKNOWLEDGEMENTS}

To Ana E Vininski, Sumako U Kinoshita (MT Laboratório), Breno FH Gondim, Daphne A de Paula and Valéria Dutra (UFMT), for assistance, and to Mauricio L Nogueira (FAMERP) and Felipe G Naveca (ILMD, Fiocruz Manaus), for providing technical training.

\section{REFERENCES}

Abad-Franch F, Grimmer GH, Paula VS, Figueiredo LTM, Braga WSM, Luz SLB 2012. Mayaro virus infection in Amazonia: a multimodel inference approach to risk factor assessment. PLoS Negl Trop Dis 6: e1846.

Aitken TG, Downs WG, Anderson CG, Spence L, Casals J 1960. Mayaro virus isolated from a Trinidadian mosquito, Mansonia venezuelensis. Science 131: 986.

Anderson CR, Downs WG, Wattley GH, Ahin NW, Reese EAA 1957. Mayaro virus: a new human disease agent. II. Isolation from blood of patients in Trinidad, B.W.I. Am J Trop Med Hyg 6: 1012-1016.

Azevedo RSS, Silva EVP, Carvalho VL, Rodrigues SG, Nunes-Neto JP, Monteiro H, Peixoto VS, Chiang JO, Nunes MRT, Vasconcelos PFC 2009. Mayaro fever virus, Brazilian Amazon. Emerg Infect Dis 15: 1830-1832.

Bronzoni RVM, Baleotti FG, Nogueira RMR, Nunes M, Figueiredo LTM 2005. Duplex reverse transcription-PCR followed by nested PCR assays for detection and identification of Brazilian alphaviruses and flaviviruses. J Clin Microbiol 43: 696-702.
Coimbra TLM, Santos CLS, Suzuki A, Petrella SMC, Bisordi I, Nagamori AH, Marti AT, Santos RN, Fialho DM, Lavigne S, Buzzar MR, Rocco IM 2007. Mayaro virus: imported cases of human infection in São Paulo state, Brazil. Rev Inst Med Trop Sao Paulo 49: 221-224.

Enserink M 2014. Crippling virus set to conquer Western Hemisphere. Science 344: 678-679.

Figueiredo LT, Owa MA, Carlucci RH, Oliveira L 1992. Laboratory diagnosis and symptoms of dengue during an outbreak in the Ribeirão Preto region, SP, Brazil. Rev Inst Med Trop Sao Paulo 34: 121-130.

Forshey BM, Guevara C, Laguna-Torres VAL, Cespedes M, Vargas J, Gianella A, Vallejo E, Madrid C, Aguayo N, Gotuzzo E, Suarez V, Morales AM, Beingolea L, Reyes N, Perez J, Negrete M, Rocha C, Morrison AC, Russell KL, Blair PJ, Olson JG, Kochel TJ 2010. Arboviral etiologies of acute febrile illnesses in western South America, 2000-2007. PLoS Negl Trop Dis 4: e787.

Galindo P, Srihongse S 1967. Transmission of arboviruses to hamsters by the bite of naturally infected Culex (Melanoconion) mosquitoes. Am J Trop Med Hyg 16: 525-530.

Mourão MPG, Bastos MDS, Figueiredo RP, Gimaque JBL, Galusso EDS, Kramer VM, Oliveira CMC, Naveca FG, Figueiredo LTM 2012. Mayaro fever in the city of Manaus, Brazil, 2007-2008. Vector Borne Zoonotic Dis 12: 42-46.

MS - Ministério da Saúde Brasil 2012. Balanço dengue. I. Janeiro a abril. Available from: slideshare.net /MinSaude/balano-denguei-jan-a-abr-2012.

Neel JV, Andrade AH, Brown GE, Eveland WE, Goobar J, Sodeman WA, Stollerman GH, Weinstein ED, Wheeler AH 1968. Further studies of the Xavante Indians. IX. Immunologic status with respect to various diseases and organisms. Am J Trop Med Hyg 17: 486-498.

Nunes MRT, Barbosa TFS, Casseb LMN, Nunes Neto JP, Segura NO, Monteiro HAO, Pinto EV, Casseb SM, Chiang JO, Martins LC, Medeiros DBA, Vasconcelos PFC 2009. Arbovirus eco-epidemiology in the area affected by the Cuiabá-Santarém Highway (BR163), Pará state, Brazil. Cad Saude Publica 25: 2583-2602.

Pinheiro FP, Freitas RB, da Rosa JFT, Gabbay YB, Mello WA, LeDuc JW 1981. An outbreak of Mayaro virus disease in Belterra, Brazil. I. Clinical and virological findings. Am J Trop Med Hyg 30: 137-142.

Potiwat R, Komalamisra N, Thavara U, Tawatsin A, Siriyasatien P 2011. Competitive suppression between chikungunya and dengue virus in Aedes albopictus C6/36 cell line. Southeast Asian J Trop Med Public Health 42: 1388-1394.

SES-MT - Secretaria Estadual de Saúde de Mato Grosso 2013. Saúde divulga dados da dengue de 2013 e o fechamento de 2012. Available from: saude.mt.gov.br/noticia/3291.

Smith GC, Francy DB 1991. Laboratory studies of a Brazilian strain of Aedes albopictus as a potential vector of Mayaro and Oropouche viruses. J Am Mosq Control Assoc 7: 89-93.

Talarmin A, Chandler LJ, Kazanji M, Thoisy B, Debon P, Lelarge J, Labeau B, Bourreau E, Vié JC, Shope RE, Sarthou JL 1998. Mayaro virus fever in French Guiana: isolation, identification and seroprevalence. Am J Trop Med Hyg 59: 452-456.

Vasconcelos P, da Rosa APAT, Pinheiro FP 1998. Arboviruses pathogenic for man in Brazil. In APAT da Rosa, PFC Vasconcelos, JFST da Rosa (eds.), An overview of arbovirology in Brazil and neighboring countries, Instituto Evandro Chagas, Belém, p. 71-99. 